\title{
Empatia com equipes multidisciplinares na fase de Ideação do processo de design Thinking
}

\section{Working with empathy in multidisciplinary teams during the Ideation phase in Design Thinking}

FERRO, Gláucia de Salles

Centro Universitário Curitiba - UNICURITIBA I glaucia@frontesul.com.br

HEEMANN, Adriano

Universidade Federal do Paraná - UFPR I adriano.heemann@gmail.com

\begin{abstract}
Resumo
Este artigo enfoca a empatia na fase de ideação do processo de design thinking. A revisão bibliográfica dos temas empatia, design thinking e equipes multidisciplinares embasam experimentos desenvolvidos para atender as demandas de um negócio social. Os resultados corroboram para a percepção de que a empatia pode ser conquistada com equipes multidisciplinares colaborativas para a construção de um escopo. Finalmente, a lacuna teórica é descrita e as oportunidades para pesquisas futuras são apresentadas.
\end{abstract}

Palavras Chave: Design thinking. Empatia. Equipes multidisciplinares. Colaboração.

\section{Abstract}

This paper focuses on empathy in the Ideation phase of the Design Thinking process. The bibliographical review on empathy, Design Thinking and multidisciplinary teams is the basis of experiments developed to meet the demands of a social business. Results corroborate the perception that empathy can be achieved through collaborative multidisciplinary teams to build a scope. Finally, the theoretical gap is described and the opportunities for future research are presented.

Key Words: Design thinking. Empathy. Multidisciplinary teams. Collaboration. 


\section{INTRODUC̣ÃO}

O propósito deste artigo é descrever experimentos realizados com 3 equipes multidisciplinares distintas visando atender às demandas de um negócio social cujo foco é o incentivo ao empreendedorismo feminino. Esses experimentos ocorreram durante um processo de Design thinking (DT) que teve por intenção definir alguns parâmetros para a estruturação de um negócio social replicável. Tais parâmetros poderiam ter sido criados a partir de processos oriundos do campo de estudo da administração, entretanto, o DT foi escolhido porque é objeto de pesquisa dos autores além de ser mais criativo, mais acessível aos usuários e aos atores envolvidos e os resultados podem ser analisados e repensados em cada fase do processo. Além disso, é baseado a empatia para a solução de desafios.

Não obstante as justificativas sobre a escolha do DT como processo para a estruturação do negócio social, cabe lembrar a própria origem do DT a partir da investigação de Buchanan (1992). Este autor resgata as raízes históricas do Design e propõe o DT contextualizado no âmbito dos Wicked Problems (RITTEL; WEBBER, 1973), âmbito no qual se instala um negócio social. Desde então o DT vem sendo aprimorado. Esse aprimoramento ocorre por conta da necessidade de se atender demandas em contextos cada vez mais complexos e, ao mesmo tempo, de se criar projetos cada vez mais adequados à realidade de seus usuários. Assim, a revisão bibliográfica apresenta os autores mais citados em pesquisas científicas e que aplicam seus próprios modelos de processo de DT em negócios ou com o propósito de inovação. Na sequência, são investigados os temas empatia e equipes multidisciplinares.

O resultado dos experimentos embasados teoricamente mostra que o processo de DT pode alcançar propósitos inesperados durante seu desenvolvimento. Tais propósitos algumas vezes são identificados como desejáveis, mas nem sempre são alcançados. Por outro lado, objetivos não idealizados surgem como parte do processo e indicam possibilidades de pesquisa. Este foi o caso destes experimentos que mostraram a relevância da empatia entre os participantes dos workshops de cocriação. Tais experimentos são apresentados neste artigo em detalhes e mostram os vieses de equipes multidisciplinares trabalhando juntas e a criação da empatia que se estabelece durante o processo. 


\section{REVISÃO DA LITERATURA}

\subsection{Design thinking}

O tema DT vem sendo investigado com mais frequência por pesquisadores de diferentes campos do conhecimento desde os anos 1990. Esta investigação iniciou nos Estados Unidos, Canadá e Reino Unido, mas só a partir dos anos 2000 passou a ocorrer com mais frequência no Brasil e em outros países (MELO; ABELHEIRA, 2015). Os autores mais citados e que tem seus modelos de processos de DT utilizados para investigações de diversas naturezas são Martin (2010) e Brown (2010).

Segundo pesquisa por assunto envolvendo os termos "Design thinking" e "Martin" realizada no portal de periódicos da Capes (2018), surgiram 69.034 resultados confirmando que o processo de DT proposto por Martin (2010) é bastante utilizado por pesquisadores. Na continuidade, a mesma forma de busca foi utilizada para "Design thinking" e "Brown" trazendo 92.770 resultados demonstrando que a proposta de Brown (2010) tem sido amplamente utilizada como referência em processos de DT.

Tais critérios teóricos de pesquisa relativos ao DT são esclarecidos para que se possa compreender a adoção do DT por autores que visam a solução de problemas complexos e que, ao mesmo tempo, buscam a inovação para diferentes práticas profissionais (NIXON, 2013; PLATNER; MEINEL; LEIFFER, 2012).

Não obstante embasamento teórico do DT, o que se pode inferir diante das pesquisas investigadas é que o DT reflete a busca por processos mais simplificados para a solução de problemas. Este fenômeno vem ao encontro da percepção de Stickdorn e Schneider (2014) que alegam que à medida que os processos de design se tornam mais transparentes e acessíveis aos usuários, um melhor entendimento do valor social do design passará a surgir. Este entendimento explica o uso do processo de DT em áreas como gestão de negócios (FRISENTAL, 2016; LOCKWOOD, 2011), saúde (MUKAI, 2012), e educação (FERRO; SILVA; HEEMANN, 2014; LEHMKUHLL; PEREIRA, 2017).

Uma vez apresentados os autores mais citados e também os campos de aplicação contemporânea do DT, cabe descrever as premissas de implantação, seus elementos, suas ferramentas e o processo em si. Para tanto o modelo de DT criado por Brown (2010) foi escolhido para este fim.

As premissas do DT se baseiam nos seguintes quesitos: empatia, insight, equipes colaborativas e multidisciplinares (BROWN, 2010). As premissas do DT são sinteticamente detalhadas no quadro 1. 
Quadro 1 - Premissas do Design thinking.

\begin{tabular}{|l|l|}
\hline Premissas & Conceito \\
\hline Empatia & $\begin{array}{l}\text { A empatia pode ser aprendida. Comportamentos não são certos } \\
\text { ou errados, mas sempre significativos. Tentativa de ver o mundo } \\
\text { por meio dos olhos dos outros. Foco na criação da empatia com } \\
\text { o usuário }\end{array}$ \\
\hline Insight & $\begin{array}{l}\text { Observação das experiências da vida cotidiana e o } \\
\text { compartilhamento dessas percepções. Visa o encontro de } \\
\text { soluções criativas para melhorar a vida das pessoas }\end{array}$ \\
\hline $\begin{array}{l}\text { Equipes } \\
\text { colaborativas e } \\
\text { multidisciplinares }\end{array}$ & $\begin{array}{l}\text { Transformação de visão da relação de pessoas com produtos } \\
\text { para a relação de pessoas com pessoas. O todo é maior que a } \\
\text { soma das partes. Interações colaborativas entre pessoas, entre } \\
\text { está desenvolvendo um projeto }\end{array}$ \\
\hline
\end{tabular}

Fonte: Os autores baseados em Brown (2010).

As características do DT são descritas por Brown (2010) ao longo da aplicação do processo e se apresentam como descrito no quadro 2.

Quadro 2 - Características do Design thinking.

\begin{tabular}{|c|c|}
\hline Características & Conceito \\
\hline $\begin{array}{l}\text { Soluções centradas } \\
\text { no usuário }\end{array}$ & $\begin{array}{l}\text { As necessidades dos usuários devem ser analisadas em todos } \\
\text { os espaços do processo de DT }\end{array}$ \\
\hline Experimentação & $\begin{array}{l}\text { Concessão a uma equipe criativa o tempo, o espaço e o } \\
\text { orçamento para cometer erros. A atitude de experimentação } \\
\text { exige uma atmosfera de otimismo }\end{array}$ \\
\hline Aspecto lúdico & $\begin{array}{l}\text { O aspecto lúdico é representado no âmbito da experimentação, } \\
\text { onde a liberdade para errar antecipadamente diminui riscos } \\
\text { futuros e testes são feitos com protótipos de baixa resolução. } \\
\text { São utilizados materiais criativos que possam representar as } \\
\text { soluções propostas }\end{array}$ \\
\hline $\begin{array}{l}\text { Pensamento } \\
\text { integrativo }\end{array}$ & $\begin{array}{l}\text { Ampliação do escopo de informações relevantes para o } \\
\text { problema; percepção das relações multidirecionais como fonte } \\
\text { de inspiração e não de contradição; identificação de padrões; } \\
\text { síntese de novas ideias }\end{array}$ \\
\hline $\begin{array}{l}\text { Pensamento } \\
\text { divergente e } \\
\text { convergente }\end{array}$ & $\begin{array}{l}\text { Tem por meta multiplicar opções para criar escolhas. É uma } \\
\text { forma prática de decidir entre alternativas existentes. }\end{array}$ \\
\hline Pensamento visual & $\begin{array}{l}\text { Uso de desenhos esquemáticos para expressar ideias visando } \\
\text { resultados diferentes e mais rápidos }\end{array}$ \\
\hline
\end{tabular}

Fonte: Os autores baseados em Brown (2010).

A partir da apresentação das premissas e dos elementos do DT, faz-se necessário o entendimento do processo do DT (figura 1) que, conforme Brown (2010), é iterativo, ilimitado e neutro. 
Figura 1 - Modelo de Processo de DT.

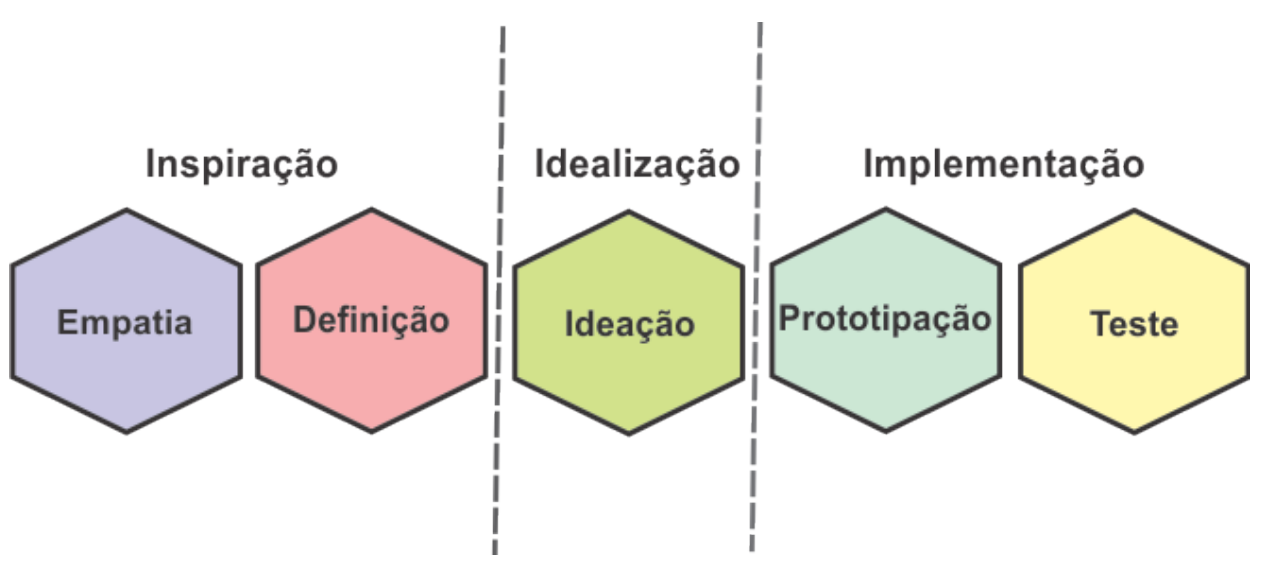

Fonte: Os autores baseados em Brown (2010).

O processo representado na figura 1 tem suas fases assim descritas:

- Fase de Inspiração - Espaço de insights no qual são coletadas informações de todas as fontes possíveis visando obter soluções para um problema;

- Fase de Idealização - Espaço de geração, desenvolvimento e teste de ideias;

- Fase de Implementação - Espaço onde melhores ideias são planejadas, prototipadas e testadas para serem lançadas no mercado.

No processo, cada fase é chamada de espaço porque se fossem etapas comuns e sequenciais não dariam margem à sobreposição e nem à iteratividade.

Para se estabelecer um processo de DT com resultados satisfatórios se faz necessário o uso de ferramentas visuais, lúdicas e que possibilitem interações de equipes multidisciplinares. No quadro 3 são apresentadas algumas dessas ferramentas.

Quadro 3 - Ferramentas que podem ser utilizadas no processo de DT.

\begin{tabular}{|l|l|}
\hline Ferramenta & Descrição \\
\hline Mapa de empatia & $\begin{array}{l}\text { Ferramenta de síntese das informações sobre o cliente numa } \\
\text { visualização do que ele diz, faz, pensa e sente. Possibilita a } \\
\text { organização dos dados de forma a prover entendimento de } \\
\text { situações de contexto }\end{array}$ \\
\hline Brainstorming & $\begin{array}{l}\text { Processo peculiar de geração de Ideias criativas que não levam } \\
\text { em conta a análise crítica. Visa encontrar soluções preliminares } \\
\text { no processo de DT }\end{array}$ \\
\hline Workshop de & $\begin{array}{l}\text { Encontro organizado na forma de uma série de atividades em } \\
\text { grupo com o objetivo de estimular a criatividade e a colaboração, } \\
\text { fomentando a criação de soluções inovadoras }\end{array}$ \\
\hline
\end{tabular}




\begin{tabular}{|l|l|}
\hline \multirow{2}{*}{ Personas } & $\begin{array}{l}\text { São arquétipos, personagens ficcionais, concebidos a partir da } \\
\text { síntese de comportamentos observados entre consumidores } \\
\text { com perfis extremos. Representam as motivações, desejos, } \\
\text { expectativas e necessidades, reunindo características } \\
\text { significativas de um grupo mais abrangente }\end{array}$ \\
\hline Mapa mental & $\begin{array}{l}\text { É uma visualização gráfica, construída para simplificar e } \\
\text { organizar visualmente dados complexos em diferentes níveis } \\
\text { de profundidade e abstração. }\end{array}$ \\
\hline RGS & $\begin{array}{l}\text { A Representação Gráfica de Síntese pode ser percebida } \\
\text { como um artefato cognitivo, ou seja, um dispositivo artificial } \\
\text { projetado para manter, apresentar ou operar informação, e que } \\
\text { cumpre uma função comunicacional }\end{array}$ \\
\hline
\end{tabular}

Fonte: Os autores baseados em Norman (1991), Brown (2010) e Viana et al. (2012).

As ferramentas descritas no quadro 3 foram escolhidas porque fizeram parte dos workshops detalhados neste artigo, entretanto não existe uma delimitação para a escolha das ferramentas. Cada líder de processo de DT pode escolher as que forem mais convenientes para o alcance dos propósitos em cada projeto (VIANNA et al., 2012).

Em termos da implementação, um projeto desenvolvido pelo processo de DT deve ser aplicável num futuro próximo, viável para que o negócio seja sustentável e desejável sob o ponto de vista dos usuários (BROWN, 2010).

\subsection{Empatia}

A revisão teórica sobre a "empatia" neste artigo tem o propósito de elucidar o termo no âmbito do design. No entanto, como a expressão originalmente vem dos campos de estudos da filosofia e da psicologia, inicia-se a pesquisa com breves conceituações advindas desses campos do conhecimento. Acrescenta-se ainda algumas contribuições dadas por neurocientistas.

Na filosofia a empatia é considerada como união ou fusão com outros seres ou objetos (EMPATIA..., 1988, p. 325). Ferreira por outro lado, define o termo "empatia" como a tendência para sentir o que se sentiria caso estivesse na situação e circunstâncias experimentadas por outra pessoa. Essa definição proposta por Ferreira é embasada em referências históricas vinculadas à psicologia (EMPATIA...2008, p. 776). Assim, até meados dos anos 1940, o tema "empatia" foi objeto de estudo de pesquisadores como Freud, Alport e Reik (WISPÉ, 1987). No entanto, somente na década de 1950 o termo foi explorado empiricamente por meio de Carl Rogers no campo da psicologia e, mais tarde no campo da educação (FERRARI, 2008). 
Por outro lado, a neurociência descobriu em meados de 1995, que os "neurônios espelho" (que é um neurônio motor) justificam a empatia pelo viés do sistema nervoso (LEVADA; FIERI; PIVESSO, 1996). A empatia neste caso ocorre quando os neurônios espelho de uma pessoa são acionados quando outra pessoa desempenha uma ação específica. Neste sentido, os neurônios-espelho da primeira pessoa adotam a perspectiva da outra pessoa como se estivesse executando a simulação de uma realidade virtual (RAMACHANDRAN, 2009).

Adentrando a investigação sobre a empatia no campo do design emocional, Ribeiro e Nojima (2013) observam que a empatia não pressupõe necessariamente uma preocupação com o bem-estar do outro, mas antes, pressupõe uma emoção de ordem identitária projetada em outrem.

Como se pode notar, embora a empatia continue sendo objeto de estudo de diferentes campos do conhecimento, é por meio da psicologia que o termo vem sendo compreendido e aplicado (SAMPAIO; CAMINO; ROAZZI, 2009).

Neste sentido, a empatia no processo de DT proposto por Brown (2010) sugere que as soluções desejáveis para o desafio de um projeto sejam pautadas nas necessidades do usuário. Assim sendo, a empatia é o caminho para que essa percepção aconteça de modo aprofundado. Corroborando com esse entendimento, Pinheiro e Alt (2012, p. 53) afirmam que não existe DT sem um grande esforço de observar, conhecer, entrevistar e compreender as pessoas que você quer servir. Sem essas averiguações relativas ao usuário, não há como se estabelecer a empatia.

Sob o aspecto empírico, Stickdorn e Schneider (2012) que investigam o DT de serviços, constroem a percepção de que o design se propõe a colocar os stakeholders no centro do design de serviços e, de preferência, cocriar com eles. Num contexto mais mercadológico, os mesmos autores afirmam que é necessário entender o valor e a natureza das relações entre pessoas, entre pessoas e coisas, entre pessoas e organizações e também entre organizações e organizações. Este entendimento direciona a aplicação do conceito de empatia para além da criação de produtos e serviços, mas para a cocriação de soluções mais complexas envolvendo aspectos culturais das pessoas e das organizações.

Ainda sob o aspecto empírico Mootee (2013) se apresenta como um autor que direciona sua pesquisa para o DT aplicado a negócios e, em sua visão, a empatia se dá quando o DT procura reinserir qualidades centradas no homem em um novo contexto de forma que possa produzir um novo significado para este contexto. Este fenômeno pode ocorrera partir de conversas reais sobre as histórias pessoais, sonhos e desejos que definem cada trabalhador, cada time e cada unidade de negócios para produzir narrativas culturais que possam ser difundidas em um universo global. 


\title{
2.3 Equipes Multidisciplinares
}

A revisão da literatura acerca da expressão "equipes multidisciplinares" tem por objetivo a compreensão deste fundamento do processo do DT. Assim, Dias e Amaral (2006) sugerem uma reflexão sobre um tema que antecede a multidisciplinaridade, que é a interdisciplinaridade aplicada ao design.

\begin{abstract}
Para alguns, tendo em vista a complexidade da sociedade atual, é necessário analisar os problemas com lentes múltiplas, levando em conta o maior número possível de pontos de vista e de perspectivas de análise. Para outros, a interdisciplinaridade decorre dos questionamentos sobre os limites entre as disciplinas e a organização do conhecimento e sobre a possibilidade de chegar-se à unificação do saber (DIAS; AMARAL, 2006).
\end{abstract}

A partir de tal reflexão é possível explorar o tema multidisciplinaridade baseado na percepção da necessidade da conexão entre as diferentes disciplinas não apenas para o alcance da unificação do saber, mas também para a exploração dos vieses de conhecimento que podem enriquecer um projeto.

Para a continuidade da investigação da expressão "equipes multidisciplinares" recorreu-se à Ferreira (2008) que entende que "equipe" é um grupo de pessoas que juntas se aplicam a uma tarefa ou trabalho. Já "multidisciplinar" o mesmo autor define como sendo o conjunto de múltiplas disciplinas, e, também, o aspecto pedagógico que trata do estudo pela adição de campos disciplinares independentes para aprofundar um conhecimento ou saber (FERREIRA, 2008). Por outro lado, em termos históricos no âmbito do design, o termo multidisciplinaridade passa a ser aplicado por volta dos anos 1950 na escola de Ulm na Alemanha (CARDOSO, 2008).

A partir do entendimento do conceito de equipes multidisciplinares proposto por Ferreira (2008) é possível inferir que a característica multidisciplinar de formação de equipes seja desejável para a concepção de variados tipos de projetos, inclusive projetos que utilizam o DT para alcançar os resultados almejados. Nascimento $(2008$, p. 3) exibe suas reflexões a esse respeito assegurando que as concepções benfazejas de multidisciplinaridade o são exatamente por aportarem insumos, sensibilidades, olhares, luzes e conhecimentos de fora para dentro - de modo propositivo, sugestivo e informativo. Desta forma, corroborando com Nascimento entende-se que, como os processos de design constroem projetos baseados no usuário, nada mais adequado do que envolver equipes multidisciplinares que levarão conhecimentos de fora para dentro por meio de diferentes visões. Com tais premissas, deduz-se que a multidisciplinaridade pode incrementar um conhecimento existente. 
A construção de um conhecimento que ocorre por meio de equipes multidisciplinares durante um processo de DT depende também do aspecto colaborativo. A colaboração, auxilia no desenvolvimento de tarefas complexas, onde o trabalho individual não é suficiente para o seu cumprimento (LU et al., 2007). Além disso, a combinação de diferentes pontos de vista permite que as partes vejam além de sua própria visão limitada, aumentando o potencial por inovação e criatividade (PIRINEN, 2016). A esta percepção Kanter (1994) denomina "Vantagem Colaborativa".

Tendo em vista as reflexões apresentadas, nota-se que as equipes multidisciplinares dependem de uma série de questões para que funcionem de modo efetivo, e, entre elas, está a vantagem colaborativa. Esta vantagem fica evidente nos resultados dos processos de DT (BROWN, 2010; FRASER 2012; MOOTEE, 2013).

\section{MÉTODO}

O método utilizado para o desenvolvimento deste artigo ocorreu em sua primeira fase com a revisão bibliográfica assistemática dos temas apresentados. Esta revisão não teve a intenção de exaurir a investigação sobre os temas, mas apenas fundamentar seus conceitos para embasar a análise dos experimentos. Em seguida são apresentados3 experimentos com equipes multidisciplinares diferentes. Na sequência, são analisados e discutidos os resultados que possibilitaram a apresentação da conclusão.

\section{OS EXPERIMENTOS}

Os experimentos referem-se à 3 workshops de cocriação que foram realizados com equipes multidisciplinares distintas a partir de briefings diferentes. Os workshops fazem parte de um processo de D Tem sua fase de ideação. Este projeto tem por propósito auxiliar a gestora do negócio social Badu Design a estruturar um modelo de micro negócio social a ser replicado com mulheres de baixa renda. A Badu Design também tem seu viés na responsabilidade ambiental, já que por meio da parceria com empresas têxteis, coleta refugos que servem de matéria prima para a confecção de novos produtos. Esses tecidos transformam-se em: bolsas, mochilas, capas de celular, capa de cadernos, capas de notebook e produtos exclusivos. Esses produtos são criados muitas vezes pelas próprias empreendedoras sob supervisão da gestora e de designers convidados. O quadro 4 apresenta de modo sintético os 3 workshops. 
Quadro 4 - Workshops de Co-criação.

\begin{tabular}{|c|c|c|c|c|}
\hline $\begin{array}{l}\text { Identificação do } \\
\text { Workshop } \\
\text { e objetivo }\end{array}$ & $\begin{array}{l}\text { Perfil dos } \\
\text { participantes }\end{array}$ & Duração & $\begin{array}{l}\text { Espaço de co- } \\
\text { criação }\end{array}$ & Resultados \\
\hline $\begin{array}{l}\text { I WORKSHOP } \\
\text { Definir } \\
\text { parâmetros para } \\
\text { a estruturação } \\
\text { da Badu Design }\end{array}$ & $\begin{array}{l}\text { Profissionais com } \\
\text { perfil de gestão } \\
\text { e de projeto } \\
\text { das áreas de: } \\
\text { Administração, } \\
\text { Economia, Tl e } \\
\text { Design }\end{array}$ & $\begin{array}{l}8 \text { horas } \\
\text { com intervalo } \\
\text { para almoço }\end{array}$ & $\begin{array}{l}\text { Sala de } 50 \mathrm{~m} 2 \\
\text { Mesa, flipchart, } \\
\text { canetas } \\
\text { coloridas, post } \\
\text { its, papeis, } \\
\text { coffee break } \\
\text { permanente }\end{array}$ & $\begin{array}{l}3 \text { visões que } \\
\text { se completam. } \\
\text { Sendo algumas } \\
\text { mais detalhadas } \\
\text { e outras mais } \\
\text { genéricas. O } \\
\text { grupo definiu } \\
\text { unificar as } \\
\text { soluções }\end{array}$ \\
\hline $\begin{array}{l}\text { II WORKSHOP } \\
\text { Definir } \\
\text { parâmetros para } \\
\text { o modelo de } \\
\text { replicação do } \\
\text { micro negócio } \\
\text { social }\end{array}$ & $\begin{array}{l}3 \text { Empreendedoras } \\
\text { de baixa renda, } \\
1 \text { designer, } 1 \\
\text { administradora e } 2 \\
\text { economistas }\end{array}$ & 4 horas & $\begin{array}{l}\text { Sala de } 20 \mathrm{~m} 2 \\
\text { Mesa, flipchart, } \\
\text { canetas } \\
\text { coloridas, post } \\
\text { its, papeis A4, } \\
\text { coffee break } \\
\text { permanente } \\
\end{array}$ & $\begin{array}{l}\text { Uma } \\
\text { representação } \\
\text { gráfica de } \\
\text { síntese de ações } \\
\text { estratégicas, } \\
\text { táticas e } \\
\text { operacionais. } \\
\end{array}$ \\
\hline $\begin{array}{l}\text { III WORKSHOP } \\
\text { Definir } \\
\text { parâmetros para } \\
\text { a definição das } \\
\text { marcas: olfativa } \\
\text { e sonora da } \\
\text { Badu Design }\end{array}$ & $\begin{array}{l}1 \text { Administradora, } \\
1 \text { designer, } \\
1 \text { arquiteta, } \\
1 \text { profissional de } \\
\text { comunicação e } \\
\text { músico, } \\
1 \text { profissional } \\
\text { de marketing e } \\
\text { músico }\end{array}$ & 4 horas & $\begin{array}{l}\text { Sala de } 20 \mathrm{~m} 2 \\
\text { Mesa, flip } \\
\text { chart, canetas } \\
\text { coloridas, post } \\
\text { its, papeis A4, } \\
\text { instrumentos } \\
\text { musicais, } \\
\text { essências } \\
\text { olfativas, } \\
\text { notebook, } \\
\text { coffee break }\end{array}$ & $\begin{array}{l}\text { Definições da } \\
\text { Persona e sua } \\
\text { história, das } \\
\text { essências da } \\
\text { marca olfativa, } \\
\text { da nota musical } \\
\text { e ritmo da } \\
\text { marca sonora. } \\
\text { Além disso, foi } \\
\text { definida a voz da } \\
\text { marca }\end{array}$ \\
\hline
\end{tabular}

Fonte: Os autores.

O 1 workshop colaborativo fez parte da construção do entendimento de como poderia ser a estrutura da Badu Design para suportar as demandas da replicação do modelo de micro negócio social. Ao mesmo tempo, um dos objetivos da empresa é replicar o negócio rapidamente para impactar o maior número de empreendedoras possível. Como mostra o quadro 4 foram convidados profissionais de diferentes áreas, mas todos apresentavam perfis de planejamento e gestão. Esses participantes se conheceram no workshop e por isso, a única empatia que ocorria preliminarmente era com a gestora e com a causa social.

O workshop começou com a apresentação de cada um. Em seguida, a gestora mostrou as dificuldades que estava enfrentando e também a visão, o propósito e os valores da Badu Design. Na sequência, a designer e líder do processo, propôs a construção de uma pergunta de projeto. Esta tarefa foi feita em duplas escolhidas aleatoriamente, depois, as duplas entraram em um consenso criando uma pergunta única. Essa pergunta serviu para iniciar e direcionar o processo de desenvolvimento da proposta de estruturação da empresa. Após a definição da pergunta os participantes ainda trabalhando em duplas foram convidados a debater sobre seus entendimentos de como deveria ser a estrutura da empresa. Assim, tiveram que representar suas percepções por meio de um mapa mental. 
A etapa seguinte foi a de apresentar os mapas mentais às demais duplas. Após as apresentações, todo o grupo foi estimulado a argumentar a respeito da viabilidade das ideias ali expostas. Esta etapa exigiu maior interação do grupo como um todo.

A última etapa foi realizada por todos os participantes por meio de reflexões e argumentações. Assim, o grupo chegou a um consenso de como deveria ser a estruturação do negócio social. A proposta apresentada resultante do consenso serviu como fonte de inspiração para a gestora repensar o modelo de replicação do negócio a partir daquela data.

O 2ำ workshop de co-criação (figura 2) ocorreu como uma forma de continuidade do primeiro. Este experimento contou com os profissionais descritos no quadro 4. Cabe ressaltar que as potenciais empreendedoras trabalham atualmente como diaristas e costureiras autônomas. Este workshop teve como propósito a percepção do entendimento de cada participante para a construção da futura rede de microempreendedoras.

Figura 2 - 2ำ workshop de co-criação



Fonte: Os autores.

Da mesma forma que o 10 workshop, as atividades iniciaram com a apresentação dos participantes e em seguida com a apresentação da gestora que elucidou acerca do desafio proposto que era como estruturar a rede Badu de microempreendedoras. Desta vez 3 pessoas se conheciam antes deste encontro e as empreendedoras se conheciam entre si. Todos conheciam a gestora.

A dinâmica desta atividade colaborativa foi diferente do workshop anterior, agestora e a designer sugeriram que fosse construída uma representação 
gráfica de síntese (RGS) para os níveis estratégico, tático e operacional da rede de empreendedoras. A proposta foi aceita e essa RGS foi construída em conjunto com todos os participantes. O desenho foi feito num painel do tipo Flip Chart.

A construção do desenho se deu a partir de sugestões do grupo. Nesta atividade foi possível notar que os profissionais mais experientes no tema gestão puderam contribuir mais com os quesitos estratégicos e táticos, enquanto as empreendedoras contribuíram mais com os aspectos operacionais. No entanto, o compartilhamento das diferentes visões fez com que cada um enriquecesse sua própria percepção da rede de empreendedores a partir daquela proposta. Assim, a empatia ao final do workshop ficou evidente. Confirmando esta afirmação uma das empreendedoras fez o seguinte comentário: "Nossa! olha só quanta coisa tem que se pensar para essa rede dar certo. A gente nem imaginava isso!"

No último workshop, o briefing foi direcionado à comunicação da marca Badu Design. A gestora entende que o incentivo ao empreendedorismo deve estar vinculado a uma marca que transmita credibilidade e que seja facilmente reconhecível por meio de percepções estéticas. Esse entendimento permitiu a idealização de um workshop colaborativo e criativo. Assim, conforme mostra o quadro $4 a$ equipe multidisciplinar foi formada por 2 musicistas, uma designer e líder das atividades, uma arquiteta e a gestora.

Para a construção da identidade Badu Design em seus vieses estéticos foi necessária a apresentação preliminar de um painel semântico construído pela gestora. Esse painel continha as informações visuais representativas dos valores da empresa.

A partir dessa apresentação, os participantes foram incentivados a criar uma persona que representasse a Badu Design. Então para dar início a essa atividade a pergunta proposta foi: Se a Badu Design fosse uma pessoa, quem ela seria?

A construção da resposta ocorreu em dois momentos, sendo o primeiro individualmente e o segundo a partir do consenso do grupo. A persona escolhida foi uma menina, alegre, decidida, pró ativa, observadora e com características de liderança.

Tendo em vista essa definição, o grupo passou a criar por meio de brainstormings e em clima descontraído as marcas sonora e olfativa, pois a marca visual estava sendo desenvolvida por outro grupo. Assim, os participantes decidiram que a marca deveria ter a sonoridade envolvendo a nota musical "Sol", o ritmo alegre e uma composição com instrumentos que transmitam alegria como o cavaquinho, o violão e o pandeiro.

Para a marca olfativa, a atividade foi realizada de forma descontraída com cada participante sentindo o aroma de essências de quatro tipos: florais, cítricas, 
amadeiradas e adocicadas. Durante a atividade as pessoas iam argumentando e escolhendo suas preferências de acordo com o briefing relacionado à criança (persona). Ao final do workshop o grupo chegou a um consenso e escolheu uma essência floral misturada com uma cítrica.

\section{RESULTADOS E DISCUSSÃO}

A partir da análise dos workshops ocorridos na fase de ideação do processo de DT foi possível perceber que todos alcançaram os objetivos propostos. Cabe lembrar que na fase de ideação conforme propõe Brown (2010), não se espera que os resultados sejam soluções perfeitas e completamente detalhadas. Almeja-se uma primeira visão do que seria a solução a partir de ideias geradas e fomentadas por ferramentas que induzem a criatividade. Após esta etapa, protótipos são construídos para validar as soluções de modo preliminar. Os protótipos podem se realizar com testes do modelo de gestão, treinamentos além de mockups de produtos. Tais testes já estão sendo realizados pela Badu Design, porém não foram apresentados porque não fazem parte da proposta deste artigo.

Partindo de tais premissas, analisa-se o resultado do primeiro workshop com as seguintes percepções: os participantes não tiveram dificuldades para acatar as sugestões das atividades propostas. A descontração provavelmente foi responsável por esta consequência; os resultados de cada etapa serviram para amadurecer a compreensão da complexidade da proposta relativa a estruturação do próprio negócio social; a multidisciplinaridade das equipes mostrou-se um fator preponderante para a diversidade de soluções idealizadas; a empatia ocorrida entre os participantes foi crescendo à medida que a aumentava a complexidade para a tomada de decisão consensual.

O segundo workshop cujo objetivo foi o de propor um entendimento de consenso de um modelo de negócio replicável, foi possível realizar as seguintes análises: a proatividade das potenciais empreendedoras desde o início do workshop foi evidente, pois mostraram-se entusiasmadas por terem sido escolhidas para representar o núcleo empreendedor do projeto; os outros participantes foram contagiados por esse entusiasmo e este fator contribuiu para que as atividades ocorressem de modo satisfatório; a diversidade profissional dos participantes enriqueceu a construção do entendimento do que deveria ser o negócio a ser replicado; a empatia entre os participantes ocorreu de forma natural e confirmou que as posturas de cada um estavam alinhadas com os valores da empresa.

O terceiro workshop que teve por propósito definir parâmetros para a construção das marcas olfativa e sonora teve um caráter mais lúdico do que os demais workshops. Partindo deste entendimento, foi possível perceber que: 
embora os musicistas tivessem um perfil pessoal mais tímido, o projeto os entusiasmou e, da mesma forma, os demais participantes refletiram esta mesma sintonia; um dos fatores que colaboraram para que ocorresse essa empatia foi a explanação da gestora em relação ao painel semântico que continha valores relativos à sua própria história de vida; na fase de criação da marca olfativa a integração do grupo foi evidente e isso fez com que as essências da marca olfativa fossem definidas por unanimidade.

Em termos da análise comparativa entre os 3 workshops e a proposta de Brown (2010) foi possível inferir que a empatia sugerida por este autor geralmente se relaciona com o usuário final, ou seja, envolver o usuário final no desenvolvimento do projeto. Nestes workshops, apenas um envolveu as potenciais empreendedoras, nos demais a empatia foi necessária entre os participantes para a idealização das propostas. Essa evidência aponta para o fato de que as equipes multidisciplinares trabalhando colaborativamente em prol de um interesse comum, podem estabelecer a empatia para o alcance de um resultado de modo eficaz.

\section{CONCLUSÃO}

Este artigo apresentou uma revisão bibliográfica assistemática com o objetivo de fundamentar alguns conceitos acerca dos temas Design thinking, Empatia, Equipes Multidisciplinares. Estes conceitos serviram para embasar 3 experimentos realizados em 3 momentos com propósitos e equipes distintas. Os elementos em comum desses workshops foram o negócio social Badu Design e sua gestora.

A descrição dos workshops demonstra que as atividades foram realizadas usando ferramentas de design que impulsionam a criatividade. Tais atividades foram desenvolvidas durante a fase de ideação de um processo de DT para cumprir os seguintes propósitos: a estruturação do negócio social para atender a demanda de sua replicação; as premissas organizacionais para o modelo de replicação e finalmente a criação das marcas sonora e olfativa. Os resultados alcançados ao final de cada workshop foram satisfatórios em termos das proposições feitas. Ao mesmo tempo, surpreenderam positivamente em termos do alcance da empatia e da efetividade da colaboração entre profissionais de diferentes áreas.

O intuito deste artigo foi o de apresentar o resultado dos workshops como uma forma de destacar a necessidade do fomento da empatia entre equipes multidisciplinares na fase de ideação em um processo de DT e não apenas do fomento da empatia para a compreensão do usuário final. Esta lacuna 
nos estudos do DT pode ser explorada em outros projetos e seus resultados podem ser mensurados comparativamente para que este aprofundamento no entendimento do processo de DT atenda a propósitos cada vez mais relevantes.

Com tais descobertas, os autores sugerem pesquisas futuras com a investigação da empatia na fase de ideação do DT. Assim, outros resultados poderão ser encontrados para o incremento de projetos de diversas naturezas por meio da colaboração com equipes muldisciplinares. 


\section{REFERÊNCIAS}

BROWN, Tim. Design thinking: uma metodologia poderosa para decretar o fim das velhas ideias. Campus, RJ: Elsevier, 2010.

BUCHANAN, Richard. Wicked problems in design thinking. Design Issues, Chicago, ILL, v. 8, n. 2, p. 5-21, 1992.

CAPES. Coordenação de Aperfeiçoamento Pessoal de Nível Superior. Disponível em: www.capes.gov.br. Acesso em: 31 jan. 2018.

CARDOSO, Rafael. Uma Introdução à história do design. São Paulo, SP: Ed. Edgard Blucher, 2008

DIAS, Maria Regina Álvares Correia; AMARAL, Leila Gontijo. A interdisciplinaridade no ensino do design. Revista Design em Foco, Salvador, BA, v. 3, n. 2, p. 49-66, 2006.

EMPATIA. In: ABBAGNAMO, Nicola. Dicionário de filosofia. São Paulo, SP: Editora Martins Fontes, 1998.

EMPATIA. In: FERREIRA, Aurélio Buarque de Holanda. Dicionário Aurélio da língua portuguesa. Curitiba, PR: Editora Positivo, 2008. p. 776.

FERRARI, Márcio. Carl Rogers, um psicólogo a serviço do estudante. 2008. https://novaescola.org.br/conteudo/1453/carl-rogers-um-psicologo-aservico-do-estudante. Acesso em: 20 dez. 2017.

FERREIRA, Aurélio Buarque de Holanda. Dicionário Aurélio da língua portuguesa. Curitiba, PR: Editora Positivo, 2008.

FERRO, Gláucia de Salles; SILVA, Arabella Galvão; HEEMANN, Adriano. Workshop de Design Thinking como parte do Processo de Avaliação no Ensino Superior em Design. In: INTERNATIONAL CONFERENCE ON DESIGN, ENGINEERING, MANAGEMENT FOR INNOVATION, 4., 2015, Florianópolis. Anais [...]. Forianópolis, SC: IDEMI, 2015. v. 1. p. 215-225.

FRASER, Heather. Como gerar inovação e crescimento nas empresas aplicando o business design: design para negócios na prática. Rio de Janeiro, RJ: Ed. Campus/Elsevier, 2012.

FRISENDAL, Thomas. Design thinking business analysis: business concept mapping aplied. Kingston, ON: Springer, 2016.

KANTER, Rosabeth Moss M. Collaborative advantage: the art ofalliances. Harvard Business Review, Philadelphia, PA, v. 72, n. 4, p. 96-108, 1994.

LEHMKUHL, Luciene; PEREIRA, Leandro Lopes. Diálogos interdisciplinares e experiências projetuais. Projética, Londrina, PR, v. 8, n. 1, p. 79-96, 2017.

LEVADA, Miriam; FIERI, Walcir José; PIVESSO, Mara Sandra G. Apontamentos teóricos de citologia, histologia e embriologia. São Paulo: Catálise Editora, 1996. 
LOCKWOOD, Thomas. Design thinking: integrating innovation, customer experience, and brand value. New York: Design Management Institute, 2009.

LU, Stephen C. Y.; ELMARAGHY, Waguih; SCHUH, Gunther; WILHELM, Robert. A Scientific Foundation of Collaborative Engineering. CIRP Annals: Manufacturing Technology, Paris, FR, v. 56, n. 2, p. 605-634, 2007.

MARTIN, Roger. Design de negócios. São Paulo: Elsevier, 2010.

MELO, Adrian; ABELHEIRA, Ricardo. Design thinking \& design: metodologia, ferramentas e reflexões sobre o tema. São Paulo: Novatec, 2015.

MOOTEE, Idris. Design thinking for strategic innovation: what they can't teach you at business or design school. New Jersey: Wiley, 2013.

MUKAI, Hitomi. Sistemas Integrados de gestão de design, qualidade, ambiente, saúde e segurança no trabalho: aplicação às pequenas e médias empresas do setor moveleiro. Tese (Doutorado em Engenharia de Produção) Universidade Federal de Santa Catarina, SC, 2012.

NASCIMENTO, Priscilla Clara Lopes do. A multidisciplinaridade imprescindível e a multidisciplinaridade disfuncional na prática e no ensino do design. In: SEMINÁRIO DO CURSO DE DESIGN DA FAU USP-DESIGN: QUO VADIS, 1., 2008, São Paulo, SP. Anais [...]. São Paulo: FAUUSP, 2008. p. 1-5.

NIXON, Natalie Weathers. Viewing ascension health from a design thinking perspective. Journal of Organization Design, Boston, v. 2, n. 3, p. 23-28, 2013.

NORMAN, David A. Cognitive artifacts. In: CARROLL, John (ed.). Designing interaction: psychology at the human-computer interface. Cambridge: Cambridge University Press, 1991.

PINHEIRO, Tennyson; ALT, Luis. Design thinking Brasil. Rio de Janeiro, RJ: Editora Campus- Elsevier, 2011.

PIRINEN, Antti. The barriers and enablers of co-design for services. International Journal of Design, Helsinki, FIN, v. 10, n. 3, p. 27-42, 2016.

PLATTNER, Hasso; MEINEL, Christoph; LEIFER, Larry. Design thinking research: studying co-creation in practice. Kingston, ON: Springer, 2012.

RAMACHANDRAN, Vilayanur. Os neurônios que moldaram a civilização. 2009. http://www.ted.com/talks/lang/ptbr/vs_ramachandran_the_neurons_ that_shaped_civilization.html. Acesso em: 26 dez. 2017.

RIBEIRO, Adriana Barbosa; NOJIMA, Vera Lúcia dos Santos. Design emocional: empatia e contextualização. Arcos Design, Rio de Janeiro, RJ, v. 7, n. 2, 2013.

RITTEL, Horst.; WEBBER, Melvin. Dilemmas in a general theory of planning. Working papers from the urban \& regional development. Policy Sciences, Berkeley, CA, v. 4, n. 2, p. 155-169, 1973.

SAMPAIO, Leonardo Rodrigues; CAMINO, Cleonice Pereira dos Santos; ROAZZI, Antônio. Revisão de aspectos conceituais, teóricos e metodológicos da empatia. Psicologia, Ciência e Profissão, Brasília, DF, v. 29, n. 2, p. 212-227, 2009. 
STICKDORN, Mark; SCHNEIDER, Jakob. This is service design thinking. New Jersey: John Wiley Professional, 2012.

VIANNA, Mauricio; VIANNA Ysmar; ADLER Isabel; LUCENA, Brenda.; RUSSO, Beatriz. Design thinking: inovação em negócios. Rio de Janeiro: MJV Press, 2012.

WISPÉ, Lauren. History of the concept of empathy. In: EISEMBERG, Nancy; J. STRAYER, Janet (ed.). Empathy and its development. Cambridge: Cambridge University Press, 1987. p. 20-35. 